\title{
Corrigendum to "Mikkeli Osteoporosis Index Identifies Fracture Risk Factors and Osteoporosis and Intervention Thresholds Parallel with FRAX"
}

\author{
Ville Juhana Waris, ${ }^{1}$ Joonas P. Sirola, ${ }^{2,3}$ Vesa V. Kiviniemi, ${ }^{4}$ \\ Marjo T. Tuppurainen, ${ }^{3,5}$ and V. Pekka Waris ${ }^{1}$ \\ ${ }^{1}$ Department of Orthopaedics, Mikkeli Central Hospital, 50100 Mikkeli, Finland \\ ${ }^{2}$ Department of Orthopaedics, Kuopio University Hospital, 70211 Kuopio, Finland \\ ${ }^{3}$ Bone and Cartilage Research Unit (BCRU), Clinical Research Center, Kuopio University, 70211 Kuopio, Finland \\ ${ }^{4}$ Department of Statistics, Kuopio University, 70211 Kuopio, Finland \\ ${ }^{5}$ Department of Obstetrics and Gynaecology, Kuopio University Hospital, 70211 Kuopio, Finland
}

Correspondence should be addressed to Ville Juhana Waris; ville.waris@fimnet.fi

Received 20 April 2017; Accepted 8 May 2017; Published 20 August 2017

Copyright ( 2017 Ville Juhana Waris et al. This is an open access article distributed under the Creative Commons Attribution License, which permits unrestricted use, distribution, and reproduction in any medium, provided the original work is properly cited.

In the article titled "Mikkeli Osteoporosis Index Identifies Fracture Risk Factors and Osteoporosis and Intervention Thresholds Parallel with FRAX" [1], there was an error regarding the FRAX $^{\circledR}$ tool, which should be clarified as follows.

The article notes: "WHO fracture risk assessment tool FRAX integrates BMD with CRFs: age, weight/height (BMI), previous fracture, parent fractured hip, current smoking, use of glucocorticoids, use of alcohol 3 or more units/day, rheumatoid arthritis, and causes of secondary osteoporosis [14]." However, the World Health Organization (WHO) did not develop, test, or endorse the FRAX tool or its recommendations [2]. The metabolic bone disease unit at the University of Sheffield that developed FRAX was a WHO Collaborating Centre from 1991 to 2010, but treatment guidelines must undergo a formal process before they can be endorsed by the WHO.

\section{References}

[1] V. J. Waris, J. P. Sirola, V. V. Kiviniemi, M. T. Tuppurainen, and V. P. Waris, "Mikkeli osteoporosis index identifies fracture risk factors and osteoporosis and intervention thresholds parallel with frax," Journal of Osteoporosis, vol. 2011, Article ID 732560 , 7 pages, 2011.
[2] N. Ford, S. L. Norris, and S. R. Hill, “Clarifying WHO’s position on the FRAX ${ }^{\circledR}$ tool for fracture prediction," Bulletin of the World Health Organization, vol. 94, no. 12, p. 862, 2016. 


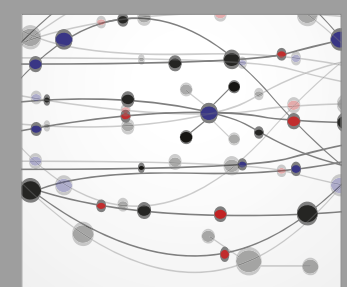

The Scientific World Journal
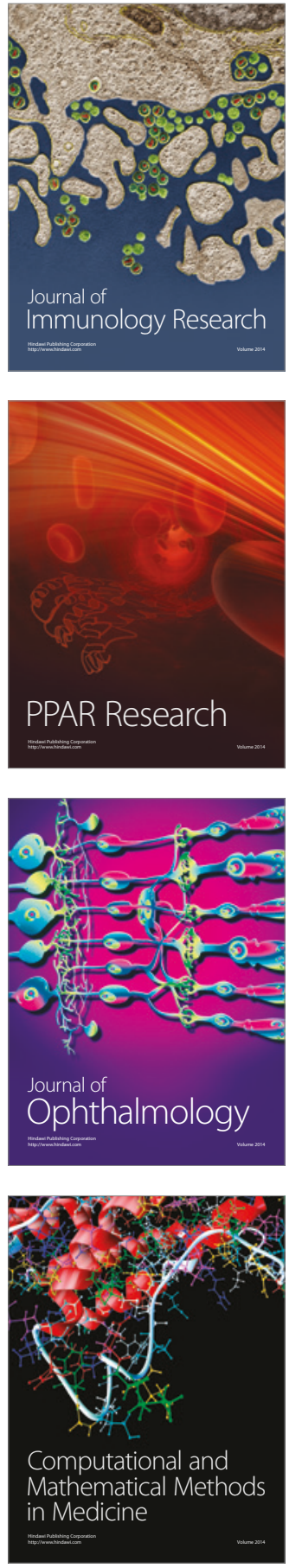

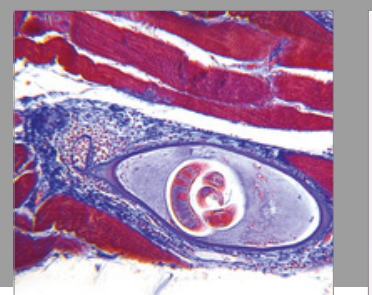

Gastroenterology Research and Practice
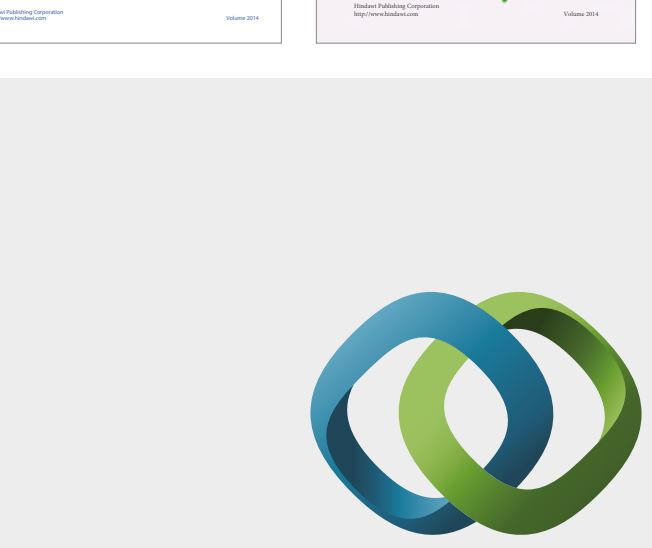

\section{Hindawi}

Submit your manuscripts at

https://www.hindawi.com
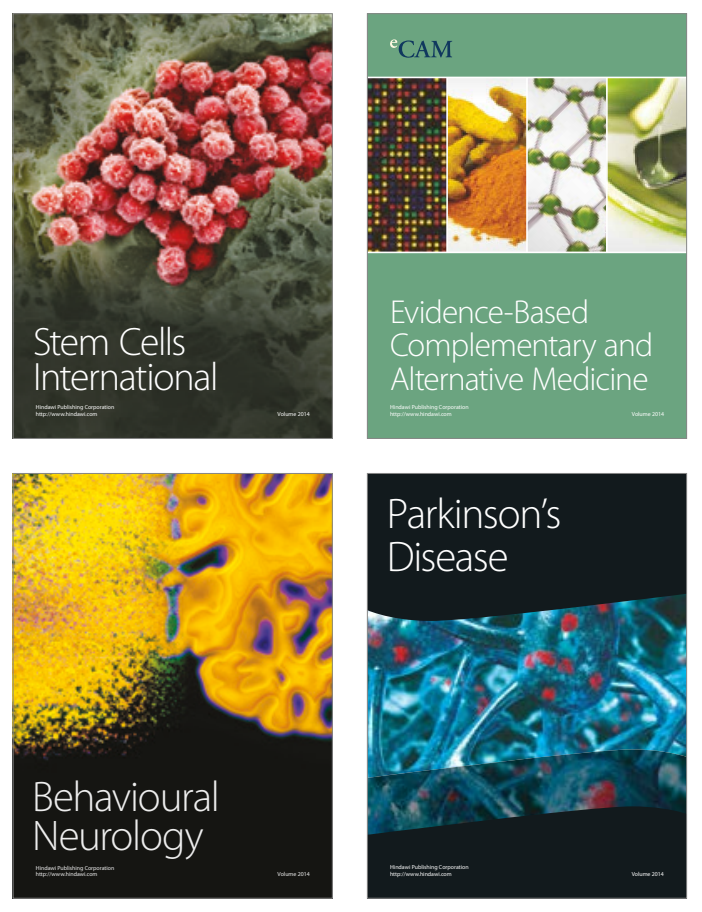
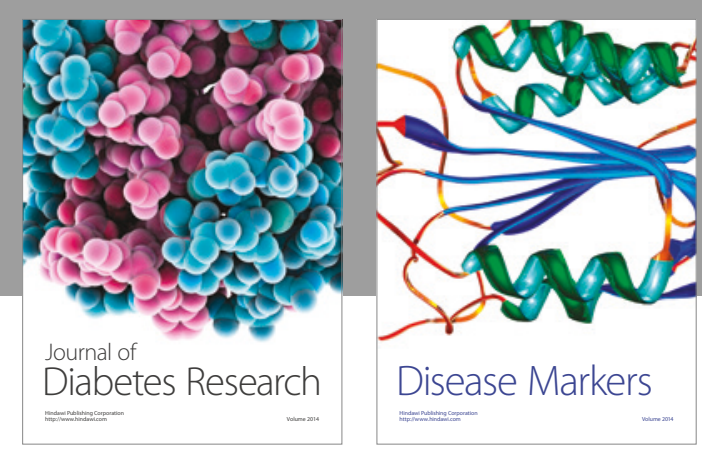

Disease Markers
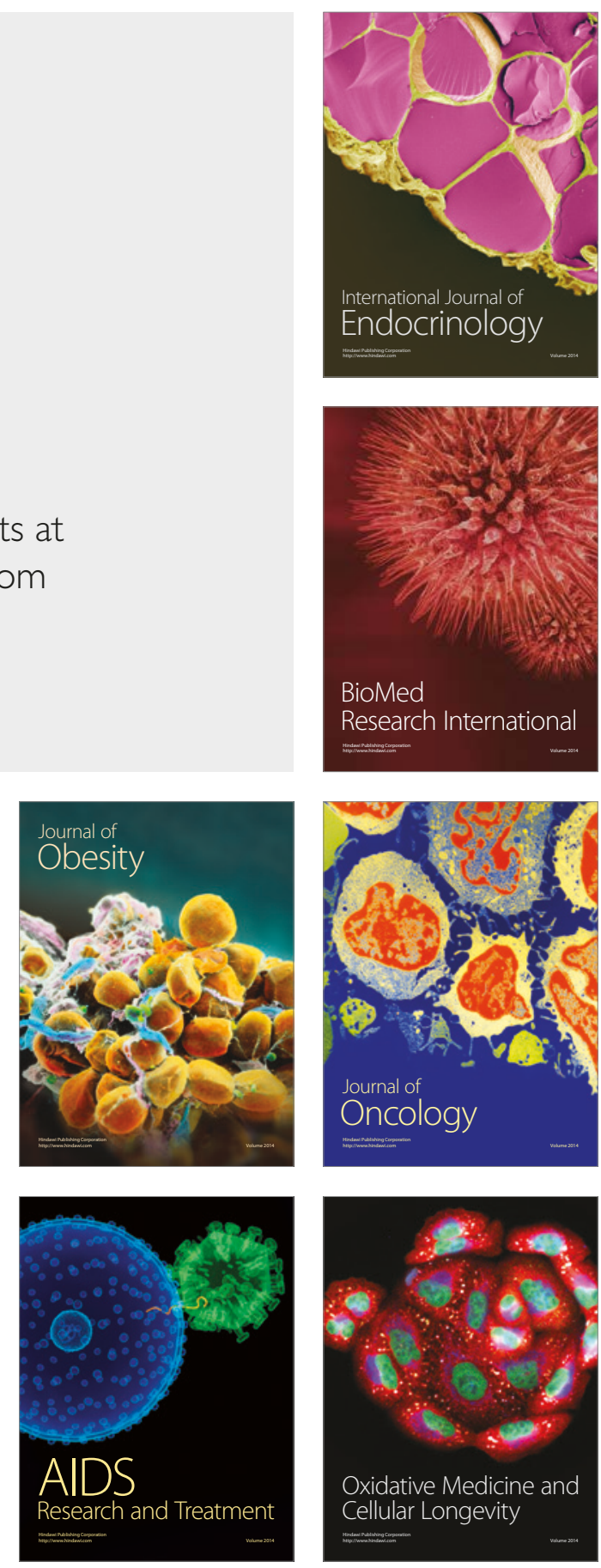